\title{
One Stage Reconstruction and Refinements for Frontonasal Encephalocele
}

\author{
DM Arman', Sk. Md. Ekramullah², Sudipta Kumer Mukherjee ${ }^{3}$, Md. Rahimullah Chowdhury4, \\ Samantha Afreen ${ }^{5}$, MA Quddus Mia ${ }^{6}$, Md. Aslam Hossain ${ }^{7}$, Mohammad Abul Kalam Azad ${ }^{8}$, \\ Md. Anwarul Hoque Faraji ${ }^{9}$
}

\begin{abstract}
${ }^{1}$ Assistant Professor, Clinical Neurosurgery, National Institute of Neurosciences and Hospital, Dhaka, Bangladesh; ${ }^{2}$ Professor \& Head, Department of Paediatric Neurosurgery, National Institute of Neurosciences and Hospital, Dhaka, Bangladesh; ${ }^{3}$ Assistant Professor, Department of Paediatric Neurosurgery, National Institute of Neurosciences and Hospital, Dhaka, Bangladesh; ${ }^{4}$ Assistant Professor, Department of Oral and Maxillofacial Surgery, Cumilla Medical College, Bangladesh; ${ }^{5}$ Registrar, Department of Paediatric Neurosurgery, National Institute of Neurosciences and Hospital, Dhaka, Bangladesh; ${ }^{6}$ Consultant, Department of Neuroanaesthesia, National Institute of Neurosciences and Hospital, Dhaka,

Bangladesh; ${ }^{7}$ Assistant Professor, Department of General Surgery, Sheikh Hasina Medical College, Tangail, Bangladesh; ${ }^{8}$ Assistant Professor, Department of Anaesthesia, BIHS General Hospital, Dhaka, Bangladesh; ${ }^{9}$ Assistant Professor, Department of Nephrology, National Institute of Kidney Diseases \& Urology, Dhaka, Bangladesh
\end{abstract}

[Received: 1 April 2019; Accepted: 20 May 2019; Published: 1 July 2019]

\begin{abstract}
Background: The successful correction of frontonasal encephaloceles was shown to depend on a detailed understanding of the pathological anatomy, careful planning of the bone movements to correct these deformities, and attention to detail regarding the placement of scars, positioning of the medial canthi and the nasal reconstruction. Objective: We reviewed our experience at the paediatric neurosurgery department of national institute of neurosciences, Dhaka, Bangladesh and discussed our evolution toward a definitive, single-stage correction, including refinements. Methodology: This was a clinical trial which was conducted in the Department of Paediatric neurosurgery at National institute of Neurosciences \& Hospital, Dhaka, Bangladesh fromMay 2014 to April 2019 for a period of five (05) years. Paediatric patients with frontonasal encephalocele were operated. Post-operative outcomes were observed. Result: A total number of 6 patients were operated. All were under 1 year. 3 were male and 3 were female. We operated 6 cases of successful one stage operation for frontonasal encephalocele in very young children. A good cosmetic result had been achieved after operation. Conclusion: In conclusion, a one-stage repair with both a transcranial and external approach is effective surgical management for the frontonasal encephalocele paediatric patients. [Journal of National Institute of Neurosciences Bangladesh, 2019;5(2): 111-117]
\end{abstract}

Keywords: : Frontonasal encephalocele; Children; One stage operation

Correspondence: Dr. DM Arman, Assistant Professor, Clinical Neurosurgery, National Institute of Neurosciences \& Hospital, Dhaka, Bangladesh; Email: armandmdr@yahoo.com; cell: +8801745771780

Conflict of interest: The authors report no conflict of interest concerning the materials or methods used in this study or the findings specified in this paper.

Funding agency: This research project was not funded by any group or any institution.

Contribution to authors: Arman DM, Ekramullah SM, Mukherjee SK, Chowdhury MR contributed from the protocol preparation, data collection up to report writing. Manuscript writing was performed by Afreen S, Quddus MA, Hossain MA.Statistical analysis was performed by Arman DM. Azad MAK, Faraji MAH involved in revision of manuscript.

How to cite this article: Arman DM, Ekramullah SM, Mukherjee SK, Chowdhury MR, Afreen S, Quddus MA, Hossain MA, Azad MAK, Faraji MAH. Surgical Management of Frontonasal Encephalocele in One Stage Reconstruction and Refinements. J Natl Inst Neurosci Bangladesh, 2019;5(2): 111-117

Copyright: C2019. Arman et al. Published by Journal of National Institute of Neurosciences Bangladesh. This article is published under the Creative Commons CC BY-NC License (https://creativecommons.org/licenses/by-nc/4.0/). This license permits use, distribution and reproduction in any medium, provided the original work is properly cited, and is not used for commercial purposes.

\section{Introductio}

Encephalocele is defined as protrusion of cranial contents (meninges and cerebral tissue) beyond the normal confines of the skull through a defect in the cranium. The population incidence of this congenital anomaly is estimated to vary from 1 per 300 to 1 per 10000 live births ${ }^{1-4}$. In respect to the incidence, cranial dysraphism, particularly encephaloceles, is far less common compared to its spinalcounterpart, namely, myelomeningocele, accounting for only 8 to $19 \%$ of all dysraphism ${ }^{4-9}$.

It is one form of a neural tube defect as are anencephaly and spina bifida $^{10}$. There are 2 main types of encephalomeningocele, frontoethmoidal and occipital, 
according to the location of the defect. Frontoethmoidal encephaloceles are herniations of the intracranial contents through a defect in the skull at the junction of the frontal and ethmoidal bones. They can be classified further as nasofrontal (between the nasal and the frontal bones), nasoethmoidal (between the nasal bones and the nasal cartilage), or naso-orbital(throughthemedial wall of the orbit). The frontoethmoidal type defect, which is located in the area of the frontal and ethmoidal bones, is exclusively common in Southeast Asia ${ }^{11}$.

The aim of surgical treatment is to restore the functional brain tissue in the cranial cavity, removal or invagination of nonfunctional extracranial cerebral tissue with water-tight closure of the dura, correct bone defect and restore esthetic facial appearance safely and successfully in a single stage. We reviewed our experience at the paediatric neurosurgery departmentt of national institute of neurosciences, Dhaka, Bangladesh and discuss our evolution toward a definitive, single-stage correction, including refinements.

\section{Methodology}

Study Design \& Place: This clinical trial was conducted from May 2014 to April 2019 for a period of five (05) years. A total number of 6 patients with frontonasal encephalocele were operated at the paediatric neurosurgery department of National Institute

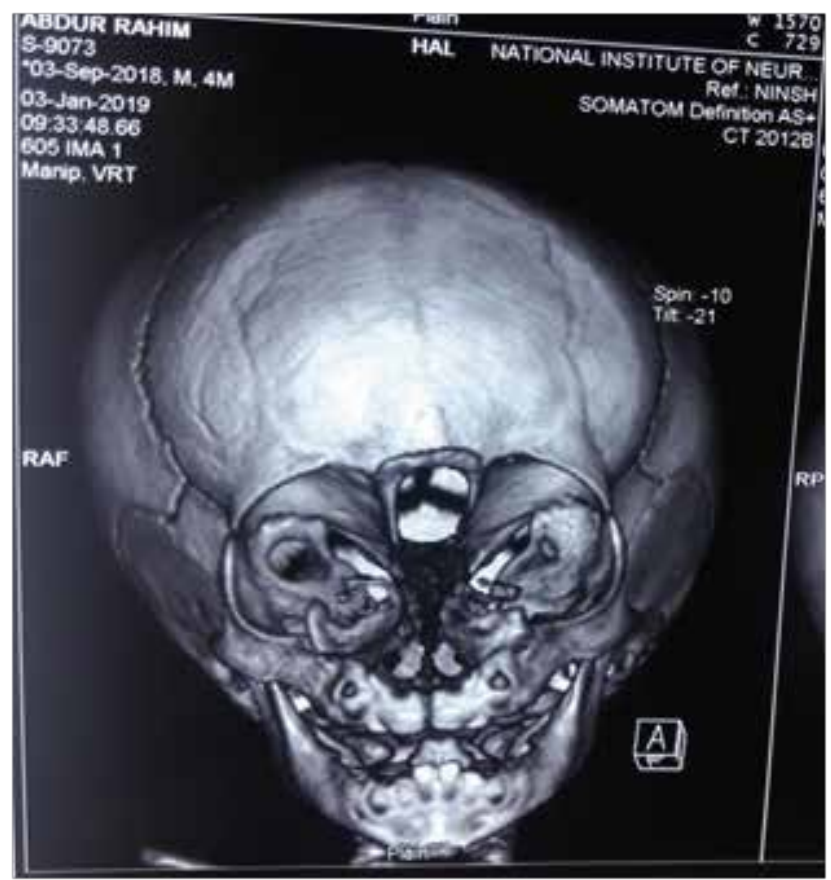

Figure I: 3D CT-scan of headshowing external bone defect of Neurosciences and Hospital, Dhaka,Bangladesh. Following information like diagnosis, extent of encephalocele, vision, procedure, intraoperative data, bone grafts, complications, and secondary procedures were collected and reviewed.

History, Presentation and Examination: All children presented with a protruding soft swelling witha wide base between the eyes.Children had been born with the facial swelling. It had slowly enlarged as they grew up.There were no complaints with regard to vision. No congenital anomalies were mentioned in their siblings. The physical examination revealed non-pulsatile swelling at root of the nose with underlying bony defect,interorbitalhypertelorism, nose deformityand medial canthal dystopia. The neurological status revealed no abnormalities.

Neuroimaging Studies: All patients were investigated with CT-scan of the head and MRIof brain that showed a defect in the anterior cranial base involving the crista galli. The defect directly communicated with the anterior cranial fossa through which herniated brain. The size andanatomical location of the lesion were noted. Associated findings, such as head size, any underlying hydrocephalus were also noted.

Surgical technique:I $\mathrm{n}$ these 6 cases the surgical approach was usually a combination of transcranial and direct anterior incisions.

We made a bicoronal scalp incision down to the anterior

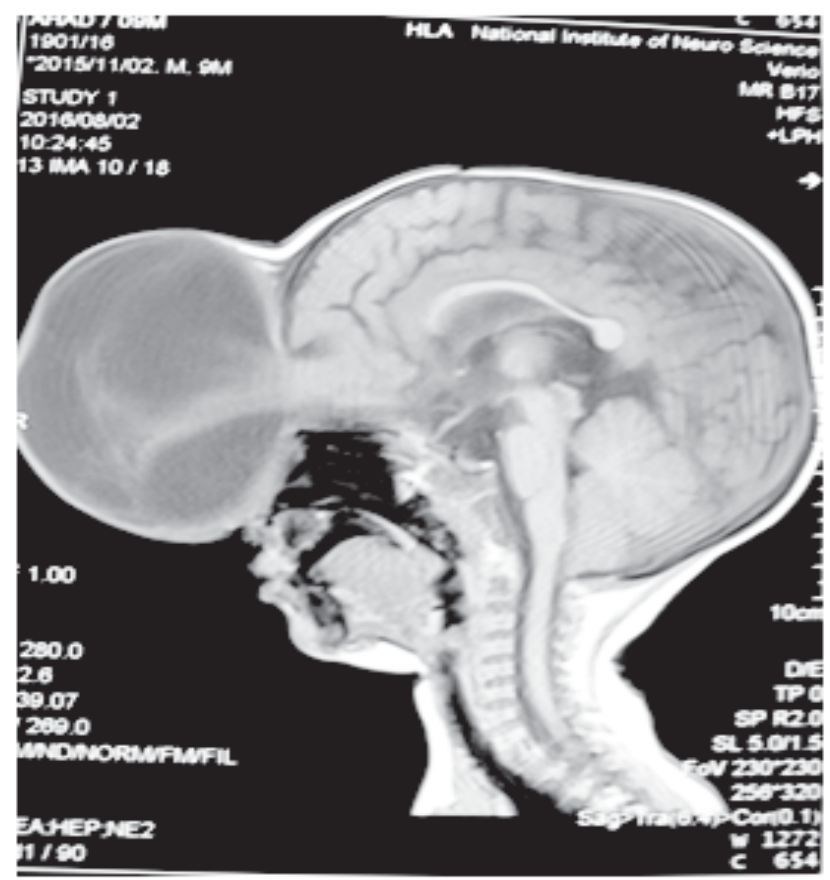

Figure II: MRI of brain showingfrontonasal encephalocele 

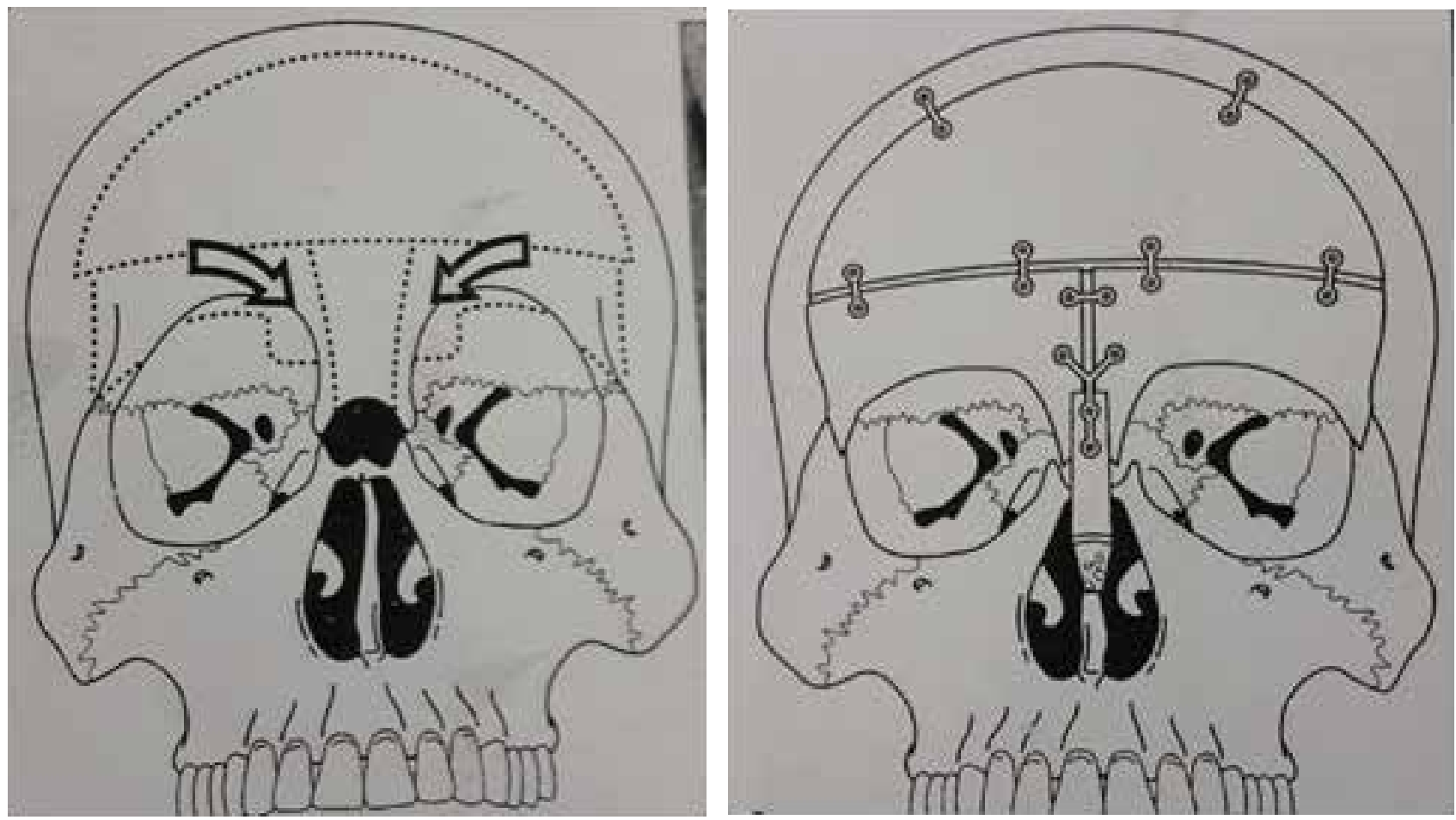

Figure III: Diagram ${ }^{12}$ shows (a) bifrontal and supraorbital craniotomies and central metopic area of bone to be removed (b) cranial and nasal reconstruction

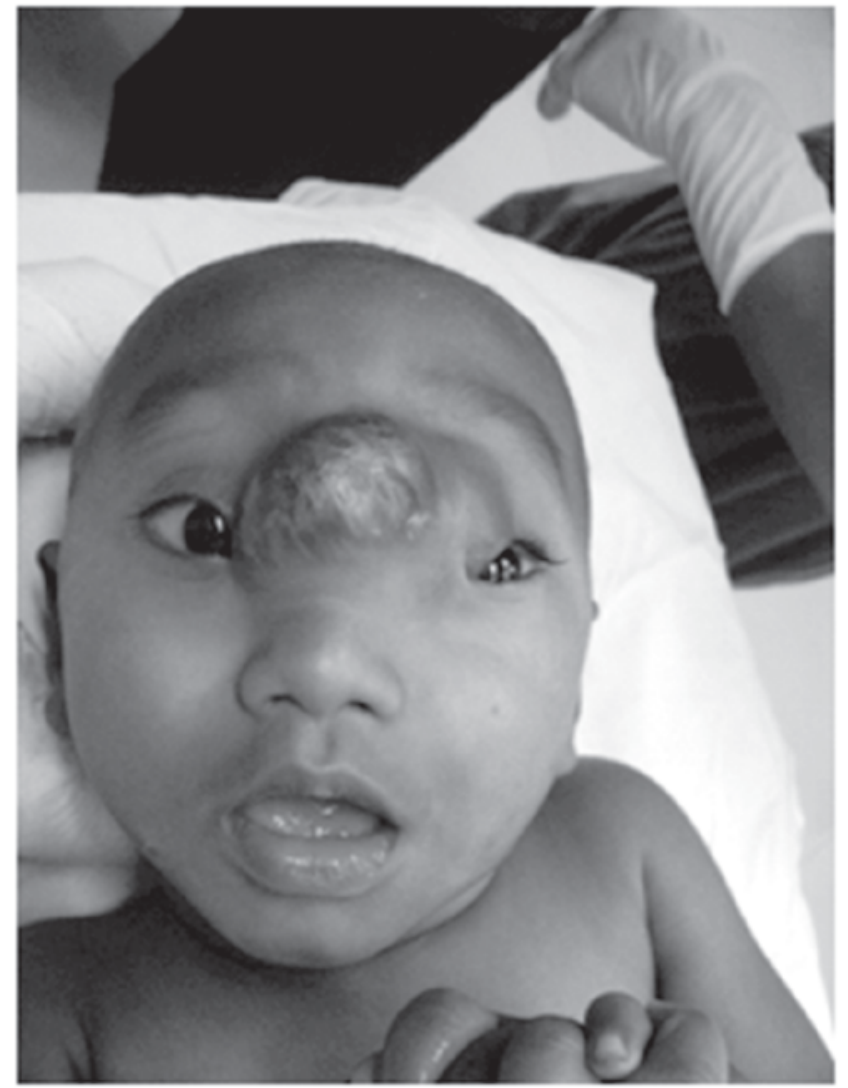

Case 1a: Preoperative photograph of 11-month-old male childwith Frontonasal encephalocele

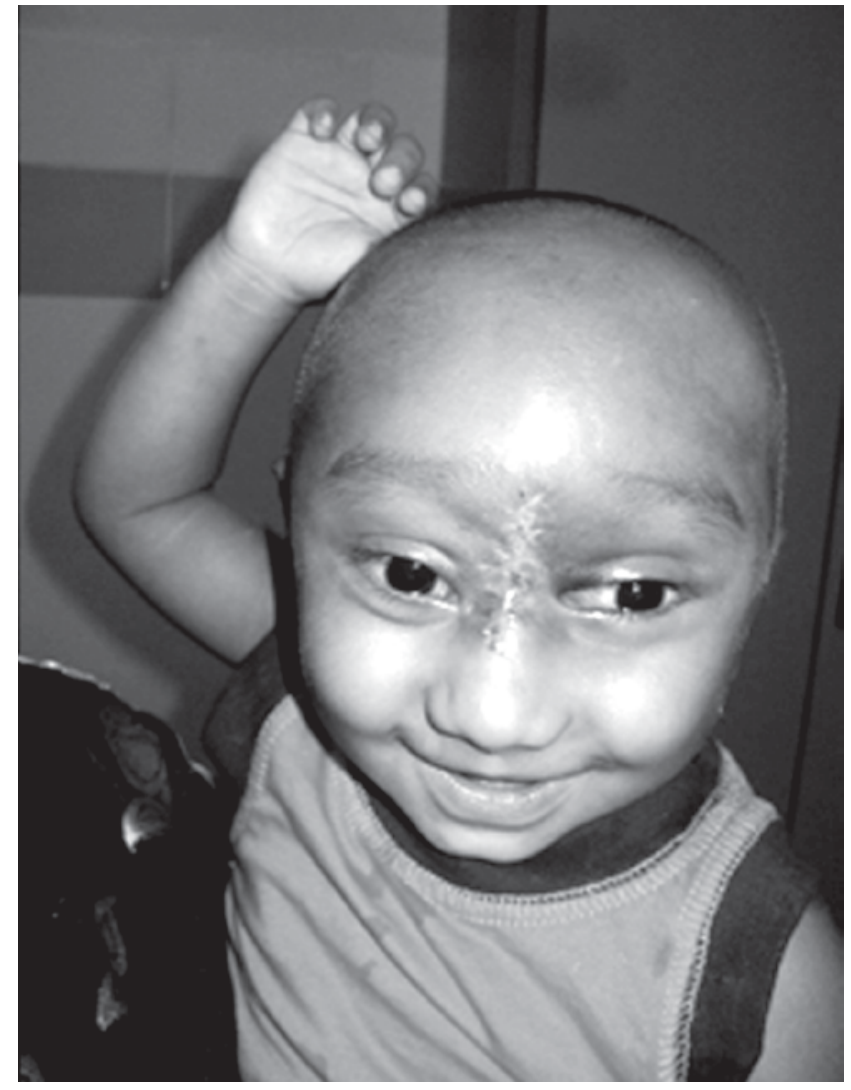

Case 1b: Postoperative photograph (after 6 weeks of operation) 
of the tragus. A paranasal skin incision was made in a reversed Y-shape because of the bilateral herniated masses in order to remove any redundant skin.The scalp was reflected to expose frontal bone both supra orbital

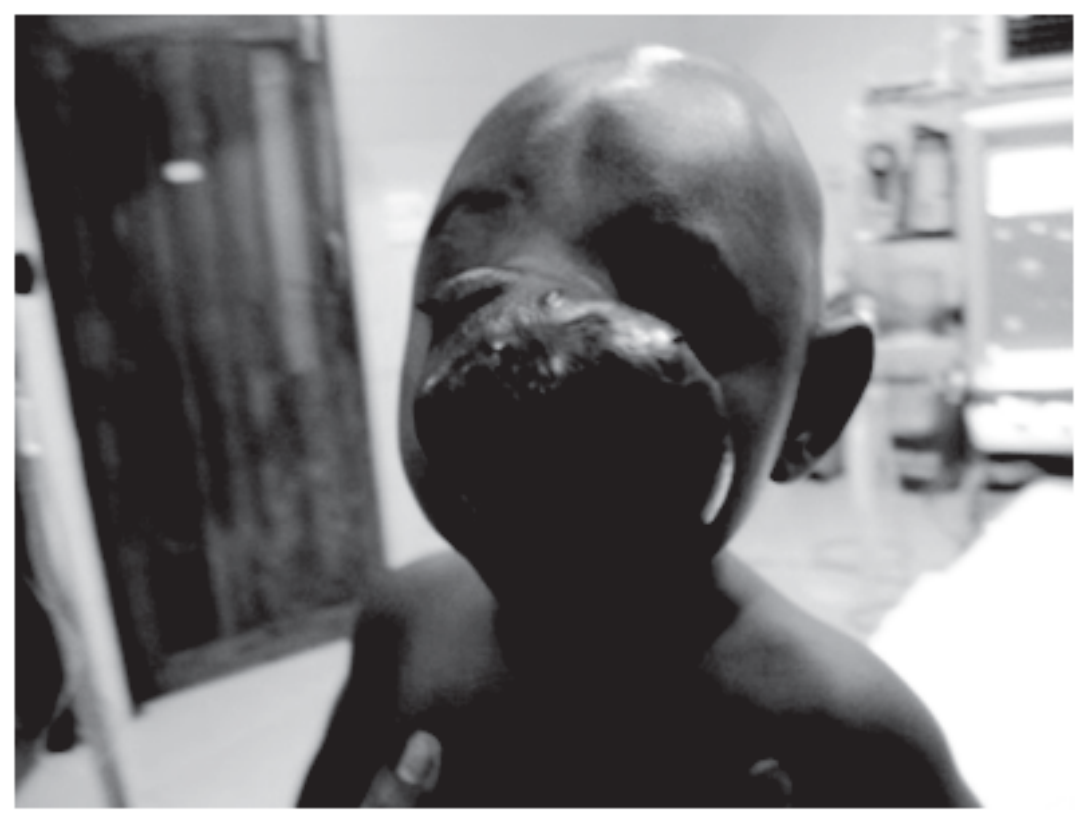

Case 2a: Preoperative photograph of 9-month-old female child with Frontonasal encephalocele

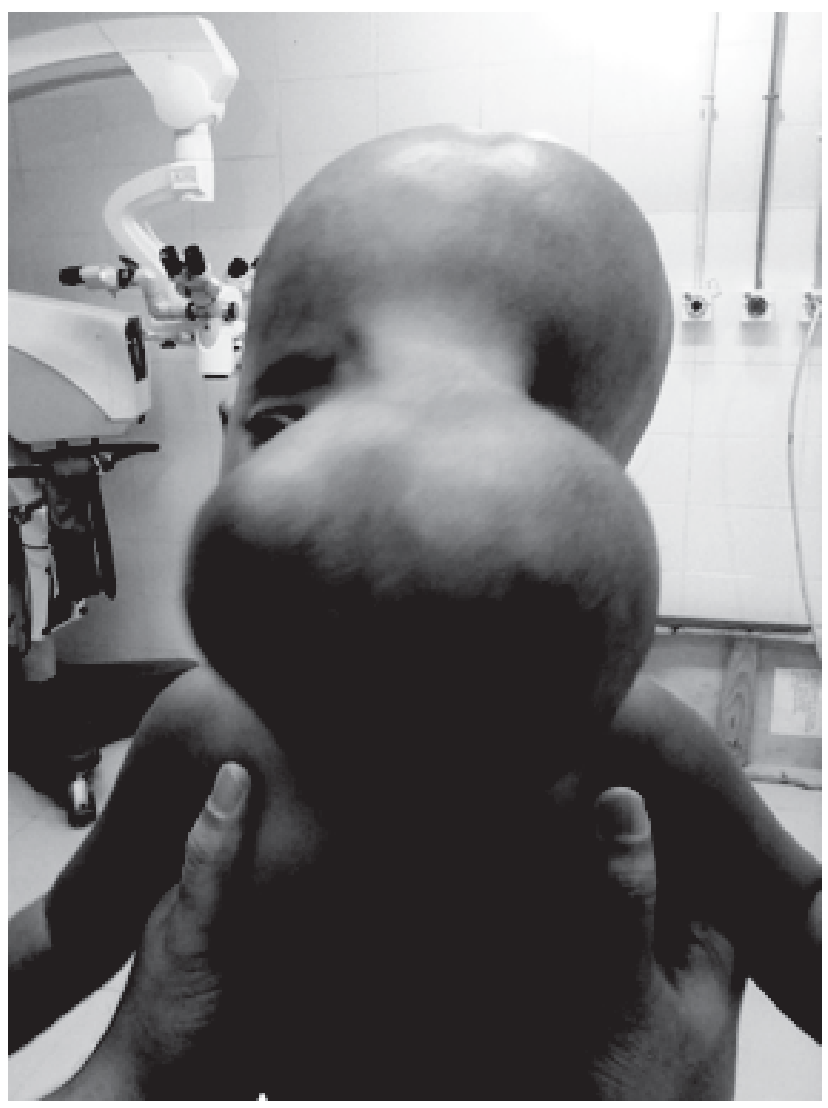

Case 3a: Preoperative photograph of 9-month-old male child with giant frontonasal encephalocele rims nasal bridge with bony defect.

A typical bifrontal craniotomy and a $\mathrm{T}$ shaped frontonasal osteotomy were done to obtain adequate exposure to the encephalomeningoceles. Supra orbital

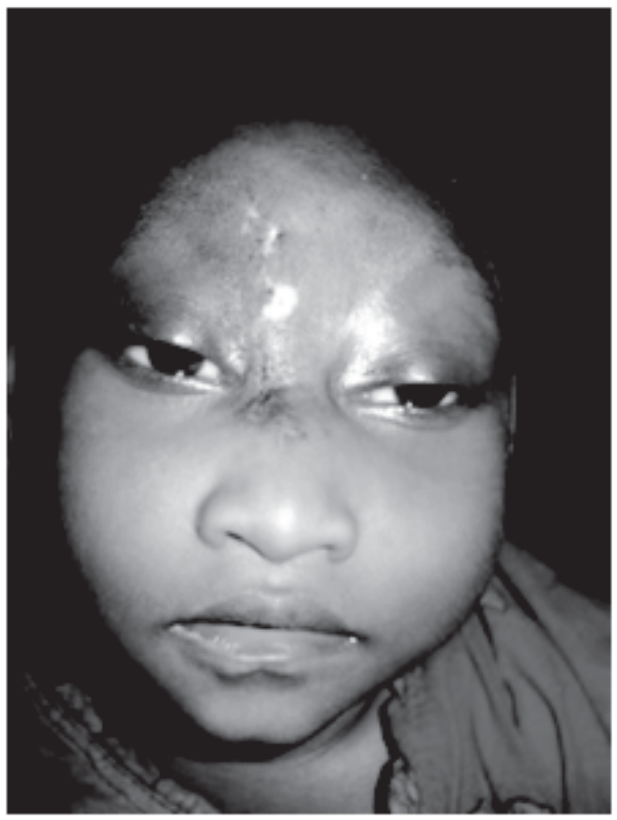

Case 2b: Postoperative photograph (after 1 month of operation)

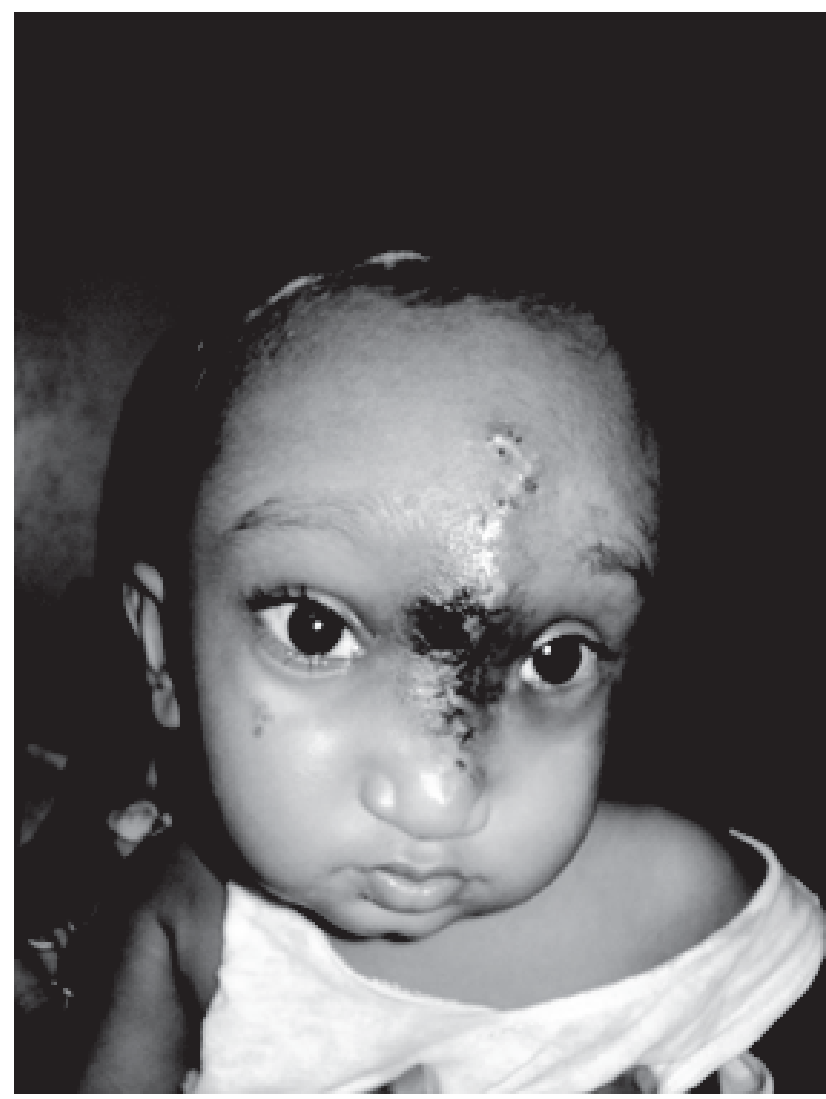

Case 3b: Postoperative photograph (after 3 weeks of operation 
rim was removed. A satisfactory extradural exposure all around the herniating glioting brain was thus achieved.The margins were freed all around the bony defect.

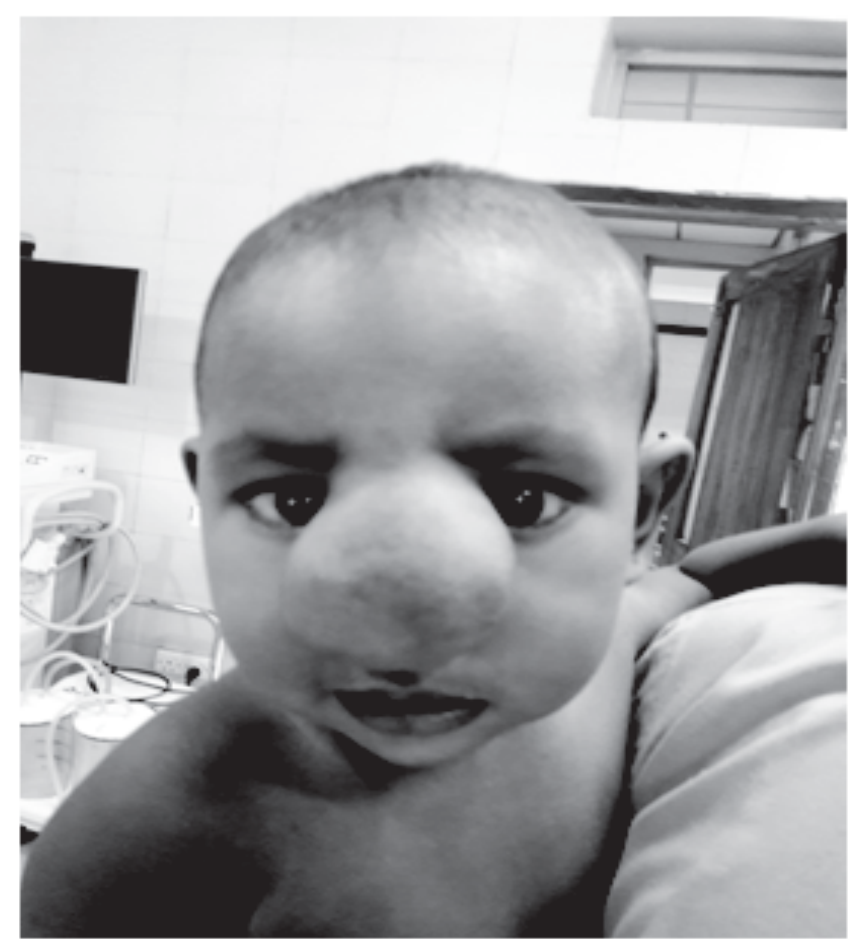

Case 4a: Preoperative photograph of 10-month-old female child with frontonasal encephalocele

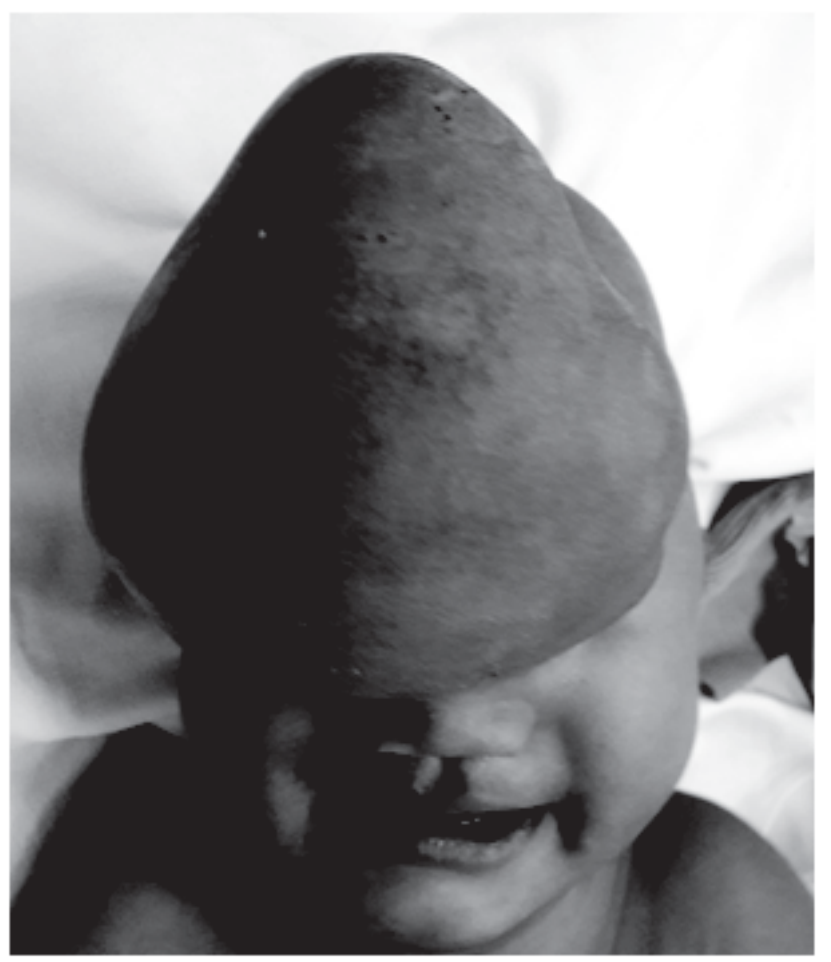

Case 5a: Preoperative photograph of 7-month-old female Child with frontonasal encephalocele
The skull defects over the inner wall of the orbit and ethmoidal sinus were located, and the herniated dura sac and the degenerative brain tissue it contained were resected. Watertight and durable closure of the dural

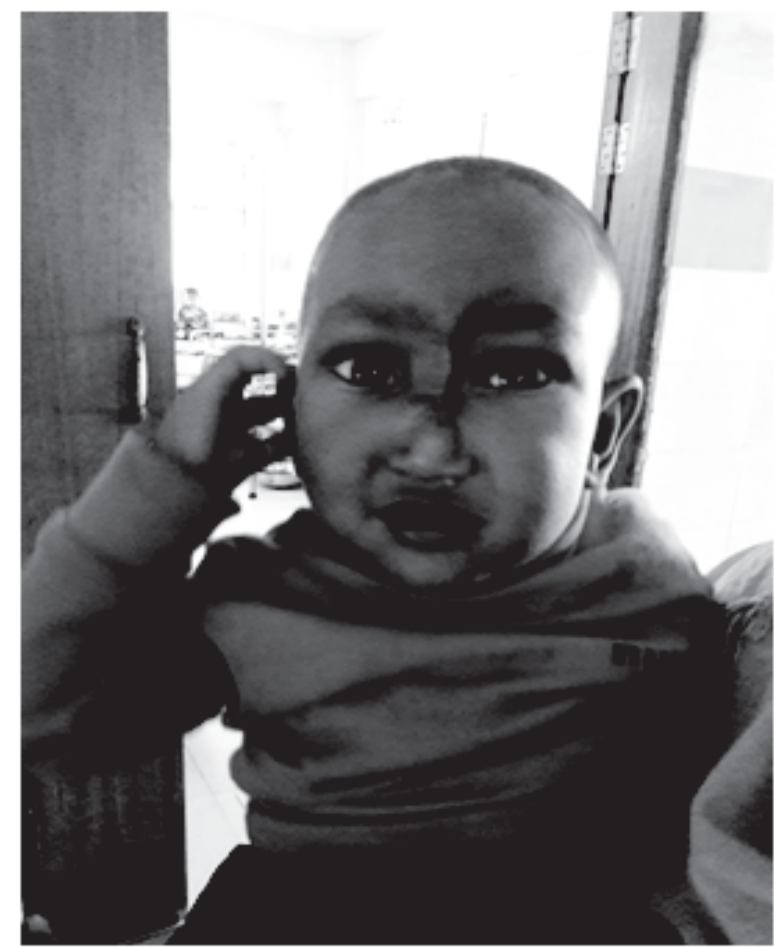

Case 4b: Postoperative photograph after 3 weeks of operation

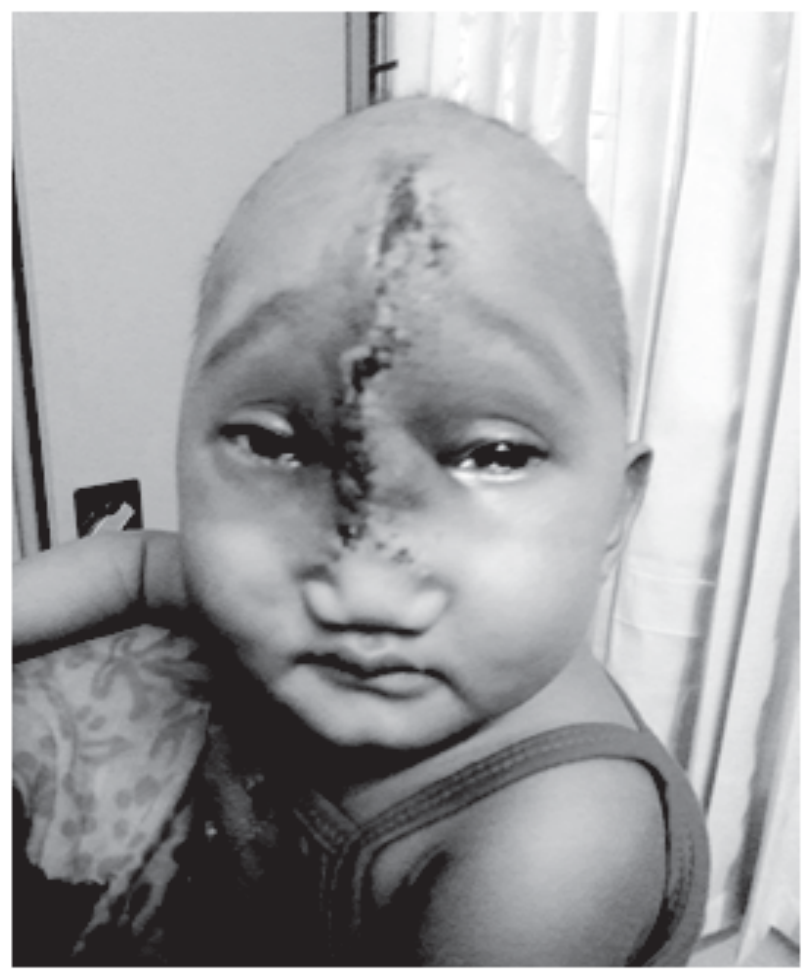

Case 5b: Postoperative photograph after 3 weeks of operation 


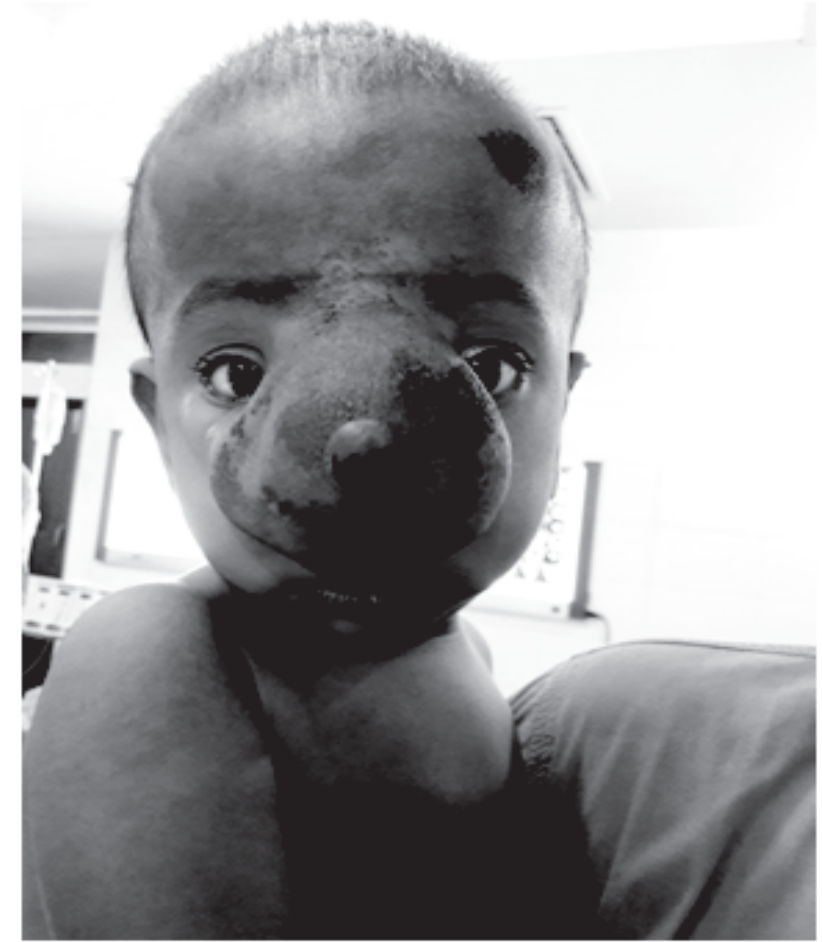

Case 6a: Preoperative photograph of 9-month-old male child with large frontonasal encephalocele

defect was achieved by an autologous pericranial graft and fibrin glues. The nasal bridge was reconstructed with split frontal bone. All areas were fixed with 2-0 proleneor by titanium miniplate and screw. The medial canthus was repositioned with prolene 3-0 stay sutures. After achieving haemostasis, wounds were closed in layers. Skin was sutured with $5 / 0$ cutting prolene.

Postoperative Courses: Post-operatively, patient recovered uneventfully except there was subgaleal CSF collection in postoperative period in two cases, managed by single aspiration.

\section{Results}

A total number of 6 patients were operated. All were under 1 year. 3 were male and 3 were female. We operated 6 cases of successful one stage operation for frontonasal encephalocele in very young children during May 2014 to April 2019 period. A good cosmetic result had been achieved after operation.

\section{Discussion}

From the anatomic aspect, the most common sites for encephaloceles are occipital and frontonasal regions. In Asia and Africa, there is a predominance of the frontonasal group while $80-90 \%$ are found in the occipital region in the Western Hemisphere. Approximately $70 \%$ of occipital encephaloceles occur in females, but there is no sex predominance noted in

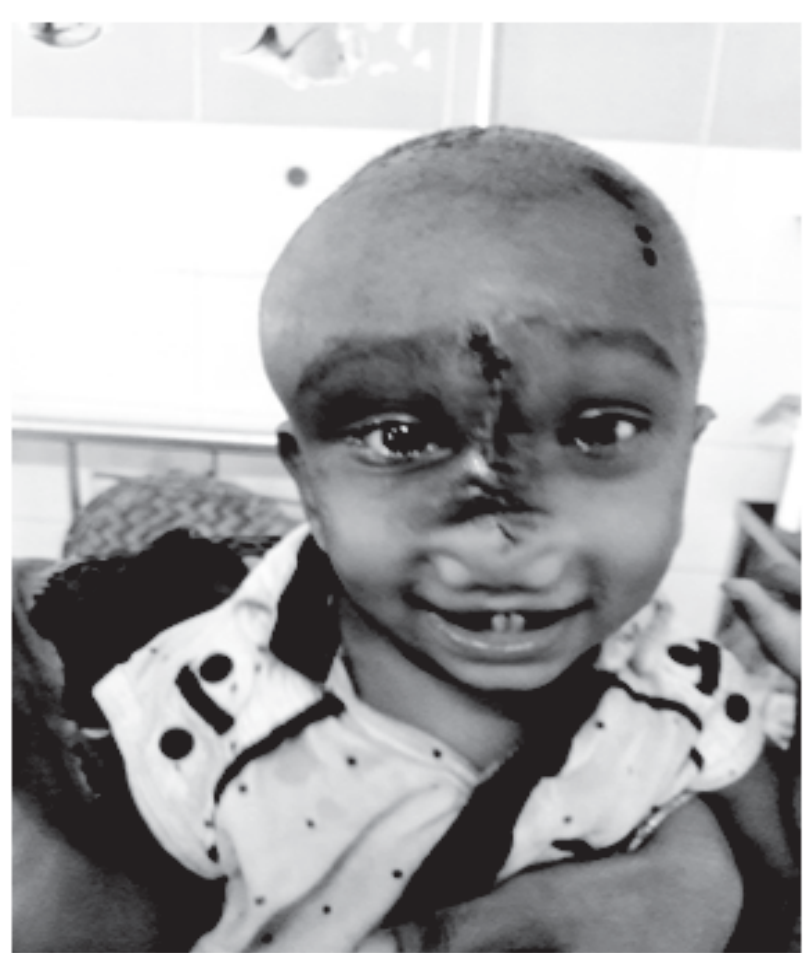

Case 6b: Postoperative photograph after 2 weeks of operation

the frontobasal type. The incidence of hydrocephalus in patients with encephaloceles is reported to be about $50 \%$. In planning the strategy of management of encephalocele, one needs to take into consideration the site, size, contents, state of CSF pathway, neurological status, associated anomalies and overall general condition of the patient. In all our cases, there was a fronto orbitonasal defect extending posteriorly up to crista galli with hypertelorism and cosmetic deformity. The principle of repair is analogous to the management of hernias in general surgery, which includes dissection of the sac, isolation of the neck, adequate closure at the neck and reinforcement. The herniated part of the brain is usually gliosed and non-viable and can usually be safely amputated. Dural defect should be closed in a watertight fashion, using graft if necessary. In our cases, watertight and durable closure of the dural defect was achieved by an autologous pericranial graft and fibrin glue. Ideally, reinforcement of bony defect with bone graft (split cranium, split rib, or acrylic) will prevent reprotrusion through the defect. Reconstruction of bony abnormalities may be necessary at times for better cosmetic results. Associated hydrocephalus should be treated by shunting before managing the encephalocele. As mentioned before, surgical approaches for encephaloceles, based on its location and type, can be direct, indirect or both. In our cases, our operative approach involved combined approach 
(bifrontal craniotomy and direct repair) and wereperformed in collaboration with the maxillofacial surgeon. We performed a typical bifrontal craniotomy with a T-shaped osteotomy for one stage reconstruction and obtained adequate exposure in order to perform dura repair and the encephalomeningocele resection.

The end result of encephalocele surgery is usually not determined by the neurosurgical procedure but by the underlying brain involvement and presence or absence of other congenital defects. In long-term follow up, cases with anterior defect have better prognosis and more than half have normal intelligence quotient (IQ $)^{13}$. Instead of the traditional 2-stage correction by preliminary disconnection and subsequent extracranial correction of the facial deformity ${ }^{14}$, a 1-stage operation has become the standard treatment ${ }^{15}$. Most Neurosurgeons and craniofacial surgeons prefer the combined nasal-coronal approach with a frontal craniotomy because of the wide exposure ${ }^{15}$. On the other hand, the frontal bone flap can also be remodeled to eliminate the trigonocephalic bulge ${ }^{12}$ repair any external skull defects, and restore an esthetic appearance such as with nasal augmentation.

Definitive bony correction is relatively easy in the infant but should be deferred for the first 4 or 5 months to lessen the risks of anesthesia and blood loss. However, the earlier the deforming stimulus of the encephalocele is removed, the less subsequent growth disturbance occurs. Ideally, infancy is the best time for definitive correction ${ }^{12}$.

The successful correction of the frontonasal encephalocele on five principles ${ }^{12}$ like accurate diagnosis, delineation of the anatomy, and surgical planning and the type of operative repair depends on the anatomic pathology of the particular lesion and the surgical resources and equipment available, osteotomies and bone movements that correct the whole deformity, including the trigonocephalic head shape and interorbital hypertelorism, nasalreconstruction that avoids the long-nose deformity, skin closure that removes abnormal skin and places incisions in advantageous locations and single-stage surgery if possible, when the neurosurgical and craniofacial expertise is present.

\section{Conclusion}

Frontonasal encephalocele is a relatively uncommon neurosurgical entity. Treatment of this condition can be rewarding if properly managed early. In this paper we present our experience in the operative management of frontonasal encephaloceles with good outcome and also share our recommendation in technical consideration for one stage surgical repair with both a transcranial and external approach.

Acknowledgments: The authors would like to thank Prof. Sk.Md.Sader Hossain (Professor and Head, Clinical Neurosurgery), Prof. Md. Badrul Alam (Professor of Neurology and Joint Director) and Prof. Quazi Deen Mohammad (Professor of Neurology and Director).

\section{References}

1. Caviness CS Jr, Evrard P: Occipital encephalocele: A pathologic and anatomic analysis. Acta Neuropath 1975;32:245-255

2. Karch SB, Urich H. Occipital encephalocele: A morphological study. J Neurol Sci 1972;15:89-112

3. Lorber J. The prognosis of occipital encephalocele. Develop Med Child Neurol 1967;13:75-86

4. Mealey J Jr, Dzenitis AJ, Hockey AA. The prognosis of encephaloceles. J Neurosurg 1970;32:209-218 5. Barrow N, Simpson DA. Cranium bifidum: Investigation, prognosis and management. AustPaediat J 1996;2:20-26

5. Eckstein HB, Macnab GH. Myelomeningocele and hydrocephalus: the impact of modern treatment. The Lancet. 1966;287(7442):842-5

6. Fisher RG, Uihlein A, Keith HM. Spina bifida and cranium bifidum: Study of 530 cases. Mayo Clin Proc1952;27:33-38

7. Matson DD. Neurosurgery of infancy and childhood, Ed. 2. Springfield III: Charles C Thomas, 1969

8. Schwidde JT. Spina bifida: Survey of 225 encephaloceles, meningoceles and myeomeningoceles. Amer J Dis Child 1952;84:35-51

9. Botto LD, Moore CA, Khoury MJ, Erickson JD. Neuraltube defects. N Engl J Med 1999; 341:1509-1519

10. Suwanwela C, Suwanwela N: A morphological classification of sincipital encephalo-meningoceles. J Neurosurg 1972; $36: 201-211$

11. Holmes AD, Meara JG, Kolker AR, Rosenfeld JV, Klug GL. Frontoethmoidal encephaloceles: Reconstruction and refinements. J Craniofac Surg 2001;12:6-18

12. Shilpakar SK, Sharma MR. Surgical management of encephaloceles. J Neuroscience. 2004;1:45-8

13. Tandon PN. Meningoencephalocoeles. Acta Neurol Scand 1970; 46:369

14. David DJ. Cephaloceles: Classification, pathology, and management-A review. J Craniofac Surg 1993; 4:192- 202

15. Forcada M, Montandon D, Rilliet B: Frontoethmoidal cephaloceles: Transcranial and transfacial surgical treatment. J Craniofac Surg 1993; 4:203-209 